\title{
Annexin II mediates the neutrophil elastase-stimulated exocytosis of mucin 5 ac
}

\author{
RUI XU ${ }^{1}$, QI LI ${ }^{1}$, XIANGDONG ZHOU ${ }^{1}$, JULIY M. PERELMAN ${ }^{2}$ and VICTOR P. KOLOSOV ${ }^{2}$ \\ ${ }^{1}$ Department of Respiratory Medicine, The Second Affiliated Hospital, Chongqing Medical University, \\ Chongqing 400010, P.R. China; ${ }^{2}$ Far Eastern Scientific Center of Physiology and Pathology of Respiration, \\ Russian Academy of Medical Sciences, Blagoveschensk, Amur Oblast 675000, Russia
}

Received May 18, 2013; Accepted November 6, 2013

DOI: $10.3892 / \mathrm{mmr} .2013 .1795$

\begin{abstract}
The overexpression and hypersecretion of mucus is a hallmark of several chronic pulmonary inflammatory diseases, including chronic obstructive pulmonary disease (COPD), asthma and cystic fibrosis. Mucin 5ac (MUC5AC) is a major component of airway mucus. Annexin II (ANXII) has been reported to be expressed in various cells and is associated with the fusion of secretory vesicles. Neutrophil elastase (NE) is present at high concentrations in the airway surface fluid in patients with cystic fibrosis and various other severe diseases. However, the role of ANXII in NE-induced secretion of MUC5AC granules remains unclear. It was determined that NE upregulates the transcription and protein synthesis of ANXII in 16HBE human bronchial epithelial cells. Following stimulation with NE, ANXII is recruited to the cell membrane, as visualised by cell immunochemistry and laser confocal microscopy, and the redistribution of ANXII is inhibited by the protein kinase-C (PKC) inhibitor bisindolylmaleimide I. Conversely, depleting endogenous ANXII decreases MUC5AC secretion into the cell culture supernatant and increases the levels of intracellular MUC5AC protein. The data indicated that ANXII is associated with the secretion of MUC5AC granules.
\end{abstract}

\section{Introduction}

The airway mucociliary clearance system is essential for innate lung defence. The major components of this system are ciliary movement and airway surface liquid, which is composed of water, electrolytes and macromolecules. Appropriate mucin secretion ensures the removal of inhaled foreign objects, including particulates and pathogens. Mucus hypersecretion is a hallmark of various pulmonary inflammatory diseases,

Correspondence to: Professor Xiangdong Zhou, Department of Respiratory Medicine, The Second Affiliated Hospital, Chongqing Medical University, 74 Linjiang Road, Yuzhong, Chongqing 400010, P.R. China

E-mail:zxd999@263.net

Key words: Annexin II, neutrophil elastase, mucin 5ac, exocytosis including chronic obstructive disease (COPD), asthma and cystic fibrosis. The gel-forming mucin 5ac (MUC5AC) is primarily synthesised by goblet cells. Airway goblet cell hyperplasia is the primary pathology in asthma and COPD (1). However, the oversecretion of gel-forming mucin, particularly MUC5AC, is generally observed in those patients who succumb to a severe asthma attack or an acute exacerbation of COPD (2).

Neutrophil elastase (NE) is primarily synthesised and released by neutrophils, which have been implicated in various mucus hypersecretory diseases. NE has been reported to be associated with goblet cell metaplasia (3) and decreased airway mucociliary clearance ability. NE induces robust MUC5AC production in human airway epithelial cells, and the upregulation of MUC5AC gene expression is mediated by the epidermal growth-factor receptor (EGFR) signalling pathway $(4,5)$. Furthermore, NE downregulates the expression of CD40, CD80 and CD86, which promotes the maturation of dendritic cells in COPD patients (6).

Annexins are a family of membrane binding proteins that regulate membrane organisation, membrane trafficking and $\mathrm{Ca}^{2+}$-related cellular processes (7). Annexin II (ANXII) is expressed in numerous cells, but is more highly expressed in cells that are poorly differentiated than in well-differentiated cells. ANXII has been implicated in the fusion of secretory vesicles and target membranes in several studies $(8,9)$. In eukaryotes, ANXII exists either as a soluble monomer (p36) or as a tetrameric complex (p90) with its specific ligand, S100A10. According to a study on chromaffin cells, the prevention of ANXII tetramer formation markedly inhibited the exocytosis of noradrenaline secretory granules (SGs) (10). Studies have demonstrated that a synthetic peptide bound to the $\mathrm{NH}_{2}$-terminal of ANXII, containing the protein kinase-C (PKC) phosphorylation site, inhibits catecholamine secretion when microinjected into chromaffin cells (11). This finding suggests a close correlation between ANXII activation and the phosphorylation of PKC (12). A study on rat lung epithelial cells revealed a time-dependent increase in ANXII expression following stimulation with acrolein (13). ANXII has been identified to correlate with $\mathrm{N}$-ethylmaleimide sensitive factor attachment protein receptors (SNAREs) in stimulated chromaffin cells (10). However, whether ANXII mediates the exocytosis of MUC5AC SGs has not been investigated. Based on the evidence mentioned above, we hypothesized that 
Table I. Primers for real-time quantitative PCR.

Forward primer

Reverse primer

$\beta$-actin

Annexin II
5'-TGGCACCCAGCACAATGAA-3' 5'-ACTTTGATGCTGAGCGGGATG-3'
5'-CTAAGTCATAGTCCGCCTAGAAGCA-3' 5'-CGAAGGCAATATCCTGTCTCTGTG-3'
ANXII mediated membrane fusion between MUC5AC SGs and the plasma membrane. We designed cellular study in vitro and attempted to reveal the specific mechanisms involved.

\section{Materials and methods}

Cells, reagents and antibodies. 16HBE human bronchial epithelial cells were purchased from Guangzhou Respiratory Institute (Guangzhou, China). Human NE (hNE) was purchased from Elastin Products Company (Owensville, MO, USA). All antibodies used for western blotting and immunocytochemistry, including mouse anti-human ANXII (ab54771), mouse anti-human mucin5ac (ab3649), fluorescein isothiocyanate (FITC)-conjugated goat polyclonal secondary antibody to mouse IgG (ab6785) and horseradish peroxidase (HRP)-conjugated goat polyclonal secondary antibody to mouse IgG (ab6789), were purchased from Abcam (Cambridge, MA, USA). The transfection reagent, FuGENE HD, was acquired from Roche (Basel, Switzerland).

Cell culture and treatment. 16HBE cells were propagated in Dulbecco's modified Eagle's medium (DMEM) supplemented with $10 \%$ foetal bovine serum (FBS), $50 \mathrm{U} / \mathrm{ml}$ penicillin and $100 \mu \mathrm{g} / \mathrm{ml}$ streptomycin in a $37^{\circ} \mathrm{C}, 5 \% \mathrm{CO}_{2}$ incubator. The $16 \mathrm{HBE}$ cells were plated in $6 \times 60-\mathrm{mm}$ culture dishes at a density of $\sim 2 \times 10^{6}$ cells $/ \mathrm{ml}$ and cultured in a $37^{\circ} \mathrm{C}, 5 \% \mathrm{CO}_{2}$ incubator to allow the cells to attach. Following serum-starvation for $24 \mathrm{~h}$, $16 \mathrm{HBE}$ cells were divided into the following groups: i) The untreated group, which was grown in serum-free DMEM to determine the basal level of MUC5AC secretion and the basal expression level and intracellular distribution of ANXII.ii) The NE-stimulated group, which was treated with $8 \mu \mathrm{g} / \mathrm{ml} \mathrm{hNE}$ for $4 \mathrm{~h}$. iii) The NE-treated and control siRNA-transfected group, which was transfected with the negative control siRNA and subsequently treated with $8 \mu \mathrm{g} / \mathrm{ml} \mathrm{hNE}$ in serum-free DMEM for $4 \mathrm{~h}$. iv) The NE-treated and ANXII siRNA-transfected group, which was transfected with ANXII siRNA and subsequently treated with $8 \mu \mathrm{g} / \mathrm{ml} \mathrm{hNE}$ in serum-free DMEM for 4 h. v) The PKC inhibitor- and NE-treated group, which was preincubated with the PKC inhibitor bisindolylmaleimide I $(500 \mathrm{nmol} / \mathrm{l})$ for $15 \mathrm{~min}$ and subsequently treated with hNE in serum-free DMEM for $4 \mathrm{~h}$.

Small interfering RNA (siRNA) preparation and transfection. ANXII-specific siRNA and the vector pGC-silencer-U6/Neo/green fluorescent protein (GFP)/ANXII (targetshRNAsequence 5'-GGTCTGAATTCAAGAGAAA-3') were synthesised and packaged by GeneChem (Shanghai, China). A base sequence containing a similar GC content was inserted into the vector as a negative control. Prior to transfection, 16HBE cells in the exponential growth phase were plated at a density of $\sim 2 \times 10^{6}$ cells $/ \mathrm{ml}$ and incubated in the culture dishes for 12 h. Following washing with phosphate-buffered saline (PBS) three times in order to avoid any interference by the antibiotics and the serum, the 16HBE cells were transfected using FuGENE HD with either ANXII siRNA or the negative control vector according to the manufacturer's instructions. siRNA concentrations were based on dose-response studies (data not shown).

Reverse transcription (RT) and quantitative polymerase chain reaction analysis $(q P C R)$. Total RNA was extracted from $16 \mathrm{HBE}$ cells in each group using TRIzol. The extraction was confirmed by RNA electrophoresis on a $1.5 \%$ agarose gel, and an absorbance $\left(\mathrm{A}_{260 / 280}\right)$ value of 1.8-2.0 was deemed acceptable. The reverse transcription followed the specifications provided in the iScript cDNA synthesis kit (Bio-Rad, Hercules, CA, USA). The synthesised cDNA was prepared for qPCR. qPCR was performed using the iQ SYBR Green supermix (Bio-Rad) with PCR primers in an iCycler (Bio-Rad). In order to quantify the expression of ANXII mRNA, $\beta$-actin mRNA served as an internal control. All primers used for qPCR are listed in Table I. The qPCR curves were analysed using the CFX Manager ${ }^{\mathrm{TM}}$ software (Bio-Rad) in order to obtain threshold cycle $(\mathrm{Ct})$ values for each sample. The mRNA expression level was calculated based on a generated standard curve.

Western blotting to detect ANXII protein. The expression of ANXII protein in each group was detected by western blotting. The cells were washed with PBS three times and lysed on ice for $20 \mathrm{~min}$ using a lysis buffer containing $10 \mathrm{mmol} / \mathrm{l}$ Tris (pH 7.4), $1 \%$ sodium dodecyl sulphate (SDS), $1 \mathrm{mmol} / 1$ sodium orthovanadate and cOmplete ULTRA protease inhibitors (Roche ID: 05892970001; Roche, Basel, Switzerland). In order to remove the nuclei and intact cells, the lysis products were centrifuged at 21,773 x g (1-14K centrifuge; Sigma Laborzentrifugen $\mathrm{GmbH}$, Osterode am Harz, Germany) for $15 \mathrm{~min}$ at $4^{\circ} \mathrm{C}$. The supernatants were standardised for equal protein concentration using the instructions in the Bicinchoninic Acid Protein Assay kit (Beyotime, Beijing, China). The samples were subsequently boiled for $5 \mathrm{~min}$ in water. Following separation with SDS-polyacrylamide gel electrophoresis, the proteins were transferred onto polyvinylidene difluoride (PVDF) membranes (Bio-Rad). The PVDF membranes were incubated with anti-ANXII (dilution, 1:100) and anti- $\beta$-actin primary antibodies (dilution, 1:1,000) overnight at room temperature. Following washing with PBS with tween-20 three times for $15 \mathrm{~min}$, the PVDF membranes were incubated with the secondary antibody, HRP-conjugated goat anti-mouse IgG, at a 1:2,000 dilution for $2 \mathrm{~h}$. The blots were visualised using enhanced chemiluminescence according to the manufacturer's instructions (KeyGen, Nanjing, China). The intensity of each 
band was measured using the Fluor-S MultiImager and Quantity-One software (Bio-Rad). The ANXII protein expression level was normalised to that of $\beta$-actin.

Cell immunochemistry and laser confocal microscopy. The direct visual observation of ANXII and intracellular MUC5AC protein were performed using immunochemistry and laser confocal microscopy. $16 \mathrm{HBE}$ cells were plated at a density of $2 \times 10^{5}$ cells $/ \mathrm{ml}$ in 24 -well plates on a glass coverslip in each well. Following culturing in a serum- and antibiotic-free environment for $12 \mathrm{~h}$, the cells were washed three times with PBS. The cells were fixed with $4 \%$ paraformaldehyde for 15 min and washed again with PBS. The fixed 16HBE cells were permeabilised with $0.1 \%$ Triton X-100 in PBS for $10 \mathrm{~min}$ and washed three times with PBS. The cells were subsequently blocked in $5 \%$ goat serum for $60 \mathrm{~min}$ and incubated with mouse anti-MUC5AC (1:500 dilution) or mouse anti-ANXII (1:50 dilution) overnight. Following three washes with PBS, the slides were incubated with the secondary antibody, FITClinked goat anti-mouse IgG (dilution, 1:1,000), for $60 \mathrm{~min}$. The cells were washed three times with PBS and embedded in $50 \%$ glycerol. The $16 \mathrm{HBE}$ cells were visualised using a confocal microscope (TCS-SP2, Leica Microsystems, Wetzlar, Germany). Representative images were captured with the incorporated digital camera and subsequently processed with Adobe Photoshop 7.0 (Adobe Systems Inc., Beijing, China).

Enzyme-linked immunosorbent assay (ELISA) for MUC5AC in the cell supernatant. Secreted MUC5AC in the 16HBE cell culture supernatant was assessed by ELISA. The culture supernatants $(50 \mu \mathrm{l} /$ well $)$ were added to a 96 -well plate and incubated at $40^{\circ} \mathrm{C}$ until dry. Following washing and blocking the wells, the mouse monoclonal antibody against MUC5AC (dilution, 1:200) was incubated in the wells for $1 \mathrm{~h}$. The plates were washed three times with PBS and incubated with $100 \mu \mathrm{l} /$ well HRP-conjugated goat anti-mouse IgG at a 1:5,000 dilution. After $1 \mathrm{~h}$, the plates were washed three times with PBS. The colour reaction was performed using an HRP solution and was stopped with $\mathrm{H}_{2} \mathrm{SO}_{4}$. The absorbance was read at $450 \mathrm{~nm}$ and the results were expressed as the ratio of MUC5AC to the standard.

Statistical analysis. Data were reported as the mean \pm standard deviation. All data were analysed with the SPSS 17.0 statistical package (SPSS Inc., Chicago, IL, USA). The analysis of one-way analysis of variance with Student-Newman-Keuls q-test was used to compare the levels of difference between groups. $\mathrm{P}<0.05$ was considered to indicate a statistically significant difference.

\section{Results}

NE increases ANXII expression in $16 H B E$ cells. The mRNA expression of ANXII was investigated in 16HBE cells following treatment with hNE. Trypan staining was used to evaluate the viability of $16 \mathrm{HBE}$ cells following treatment with hNE. Further research depended on $>95 \%$ cell viability. As shown in Fig. 1A and B, the normalized ANXII mRNA level exhibited a dose- and time-dependent increase following stimulation with hNE. However, a higher dose of $12 \mu \mathrm{g} / \mathrm{ml} \mathrm{hNE}$ or extending the stimulation time to $>4 \mathrm{~h}$ failed to induce a significantly higher transcription of ANXII in 16HBE cells (Fig. 1A and B).
Furthermore, ANXII protein in 16HBE cells was detected by western blotting. The expression levels of ANXII in $16 \mathrm{HBE}$ cells were normalized by $\beta$-actin. As shown in Fig. $1 \mathrm{C}$ a concentration of hNE ranging from 4 to $12 \mu \mathrm{g} / \mathrm{ml}$ significantly increased the synthesis of ANXII in 16HBE cells. However, no significant differences were observed between $16 \mathrm{HBE}$ cells stimulated by 8 or $12 \mu \mathrm{g} / \mathrm{ml} \mathrm{hNE}$ in the synthesis level of ANXII (Fig. 1C). Stimulation of hNE increased the expression of ANXII in 16HBE cells in a time-dependent manner. However, extending the exposure time to $>8 \mathrm{~h}$ failed to induce a further increase of ANXII expression compared with the $4 \mathrm{~h}$ exposure group (Fig. 1D).

ANXII is recruited to the cell membrane upon stimulation with $N E$. As mentioned previously, NE upregulated the expression of ANXII. To further investigate the distribution of ANXII protein in stimulated $16 \mathrm{HBE}$ cells, ANXII was visualised by cell immunochemistry. Immunoreactivity was performed using laser confocal microscopy and Leica Confocal Software. ANXII was recruited to the plasma membrane in $16 \mathrm{HBE}$ cells treated for $4 \mathrm{~h}$ with $8 \mu \mathrm{g} / \mathrm{ml} \mathrm{NE}$ but not in the untreated control cells (Fig. 2A and B). The phosphorylation of ANXII and the formation of an ANXII heterotetrameric complex (p90), which has been demonstrated to be more efficient than monomeric p36, has been reported to be dependent on the activation of PKC (14). Therefore, it was investigated whether PKC participated in the redistribution of ANXII in stimulated $16 \mathrm{HBE}$ cells. 16HBE cells were preincubated with the PKC inhibitor bisindolylmaleimide I (500 nmol/l) and subsequently stimulated with $\mathrm{NE}$, as described previously. Images were captured using a laser confocal microscope (Fig. 2C). Pretreatment with bisindolylmaleimide I markedly reduced the recruitment of ANXII to the cell membrane in NE-stimulated 16HBE cells.

ANXII is required for MUC5AC secretion in $16 \mathrm{HBE}$ cells. In order to investigate whether ANXII is required for the secretion of MUC5AC, a specific siRNA that targets ANXII was designed. The downregulation of ANXII in 16HBE cells using ANXII siRNA was verified by western blotting (Fig. 3A). The secretion of MUC5AC into the cell culture supernatant was measured by ELISA. NE increased MUC5AC secretion by $\sim 3$-fold after $4 \mathrm{~h}$. 16HBE cells transfected with ANXII siRNA secreted significantly less MUC5AC following stimulation with NE (Fig. 3B). Treatment with bisindolylmaleimide I partially reduced the secretion of MUC5AC in NE-stimulated 16HBE cells. The MUC5AC retained in the endochylema was visualised by cell immunochemistry. The retained MUC5AC in the $16 \mathrm{HBE}$ cells was quantified using the fluorescence intensity ratio and was compared with the untreated control (Fig. 3C-G). $16 \mathrm{HBE}$ cells transfected with ANXII siRNA exhibited poor levels of MUC5AC secretion following incubation with NE, and the retained MUC5AC level was significantly higher in the endochylema compared with that in the NE-treated group (Fig. 3H, P<0.05).

\section{Discussion}

Mucus hypersecretion in the human airway is a pathology present in several respiratory diseases, including asthma and COPD. Excessive mucus production in the airways has been 

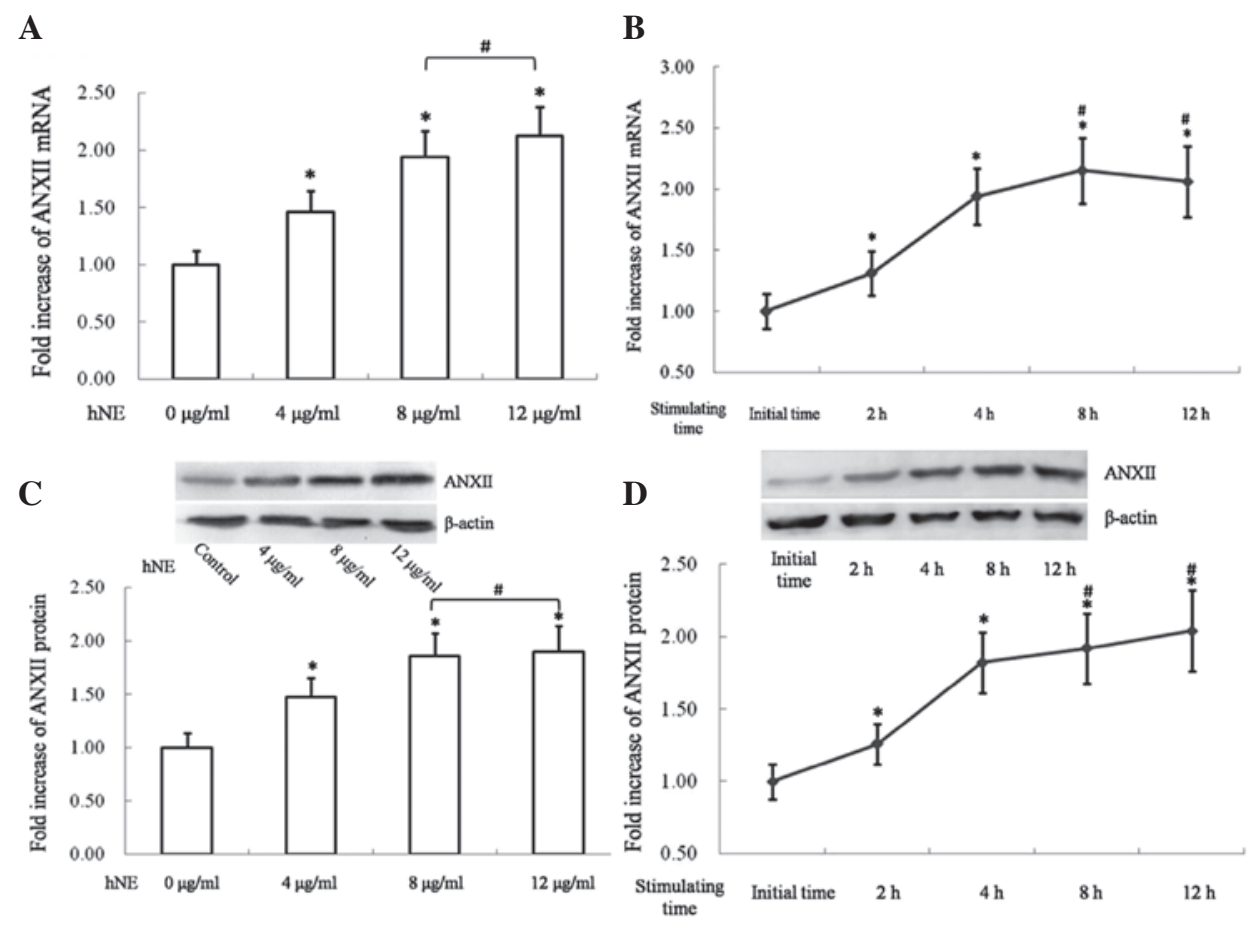

Figure 1. Annexin II (ANXII) expression in human bronchial epithelial (16HBE) cells following stimulation with neutrophil elastase (NE). (A) 16HBE cells were treated for $4 \mathrm{~h}$ with 4,8 or $12 \mu \mathrm{g} / \mathrm{ml}$ human (hNE) or serum-free Dulbecco's modified Eagle's medium as a negative control. The quantity of ANXII mRNA was determined by quantitative polymerase chain reaction (qPCR). The results were reported as the fold-increase in ANXII mRNA expression in the treatment group compared with the negative control. " $\mathrm{P}<0.05$ vs. the control group; ${ }^{\mathrm{P}} \mathrm{P}>0.05$; $\mathrm{n}=6$. (B) $16 \mathrm{HBE}$ cells were treated with $8 \mu \mathrm{g} / \mathrm{ml} \mathrm{hNE}$ for $2,4,8$ or $12 \mathrm{~h}$, respectively. The quantity of ANXII mRNA was determined by qPCR. The results were reported as the fold-increase in ANXII mRNA expression in the treatment group compared with the initial time. ${ }^{*} \mathrm{P}<0.05$ vs. the expression ANXII mRNA of the initial time; ${ }^{*} \mathrm{P}>0.05$ between the two groups; $\mathrm{n}=6$. (C) $16 \mathrm{HBE}$ cells were treated for $4 \mathrm{~h}$ with 4,8 or $12 \mu \mathrm{g} / \mathrm{ml} \mathrm{hNE}$ or serum-free DMEM as a negative control. ANXII protein levels in $16 \mathrm{HBE}$ cells were determined by western blotting. ${ }^{*} \mathrm{P}<0.05 \mathrm{vs}$. the control group; ${ }^{\# P}>0.05$ between the two groups; $\mathrm{n}=6$. (D) $16 \mathrm{HBE}$ cells were treated with $8 \mu \mathrm{g} / \mathrm{ml} \mathrm{hNE}$ for $2,4,8$ or $12 \mathrm{~h}$, respectively. ANXII protein levels in $16 \mathrm{HBE}$ cells were determined by western blotting. The results were reported as the fold-increase in ANXII protein expression in the treatment group compared with the initial time " $\mathrm{P}<0.05$ vs. the initial time and ${ }^{~} \mathrm{P}>0.05$ between the two groups.
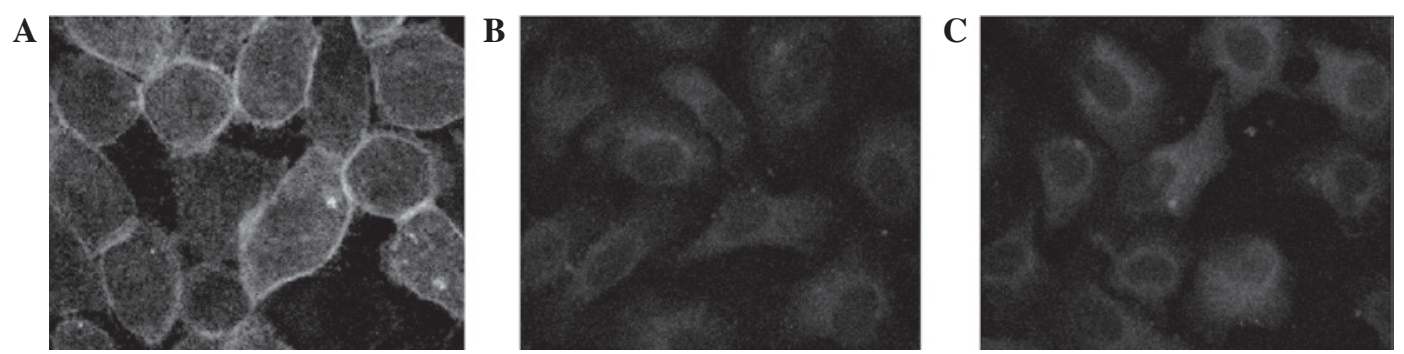

Figure 2. The intracellular distribution of Annexin II (ANXII) following treatment with neutrophil elastase (NE). Human bronchial epithelial (16HBE) cells were treated for $4 \mathrm{~h}$ with $8 \mu \mathrm{g} / \mathrm{ml}$ human NE or with serum-free Dulbecco's modified Eagle's medium as a negative control. ANXII was visualised using cell immunochemistry and laser confocal microscopy. (A) Representative image of NE-stimulated 16HBE cells (original magnification, x800). (B) Representative image of the negative control 16HBE cells (original magnification, $\mathrm{x} 800$ ). (C) Representative image of NE-stimulated 16HBE cells that were pretreated with the protein kinase-C inhibitor bisindolylmaleimide I (original magnification, $\mathrm{x} 800$ ).

linked to an increase in morbidity and mortality in patients with respiratory diseases (15). In asthma and COPD, increased numbers of goblet cells correlates with excessive mucus production. Goblet cells are capable of rapidly secreting mucus in response to certain stimuli in order to form a mucus layer that lines the airways. Highly glycosylated forms of mucin, MUC5AC in particular, form a mucus gel and may lead to severe airway obstruction (16).

As several studies have reported, the translocation and exocytosis of MUC5AC SGs is a complicated process with an obscure intrinsic regulatory mechanism. The PKC-dependent phosphorylation of myristorylated alanine-rich C-kinase substrate (MARCKS) has been demonstrated to be involved in the translocation of MUC5AC SGs $(17,18)$. Several proteins that promote mucus secretion, including interleukin (IL)-1 $\beta$, IL-6, monocyte chemoattractant protein-1 and tumour necrosis factor- $\alpha$, improve MUC5AC hypersecretion through the activation of MARCKS. The exogenous attenuation of the function of MARCKS may decrease airway mucin secretion (18).

ANXII, also termed ANXA2, is widely expressed in eukaryotic cells and is a calcium- and phospholipid-binding protein that mediates essential cellular processes, in particular membrane trafficking events. Deep-etch electron microscopy has revealed a crosslink between the SGs and the plasma 
A

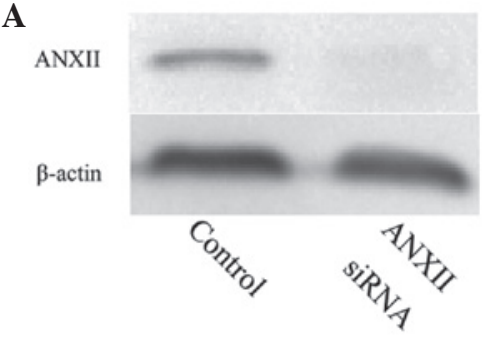

B

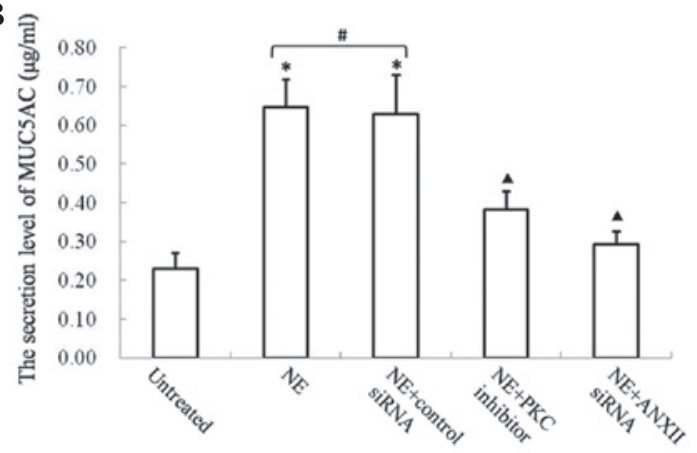

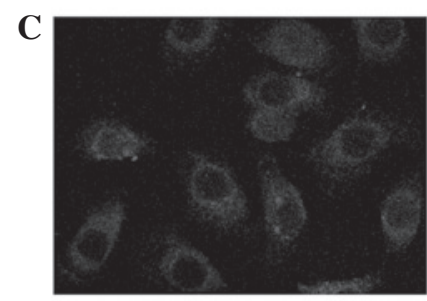
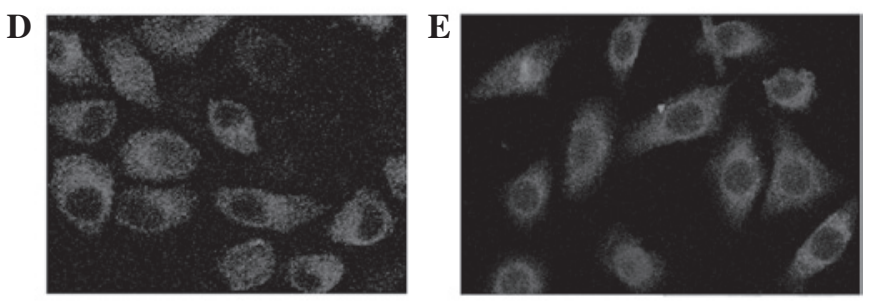

$\mathbf{F}$

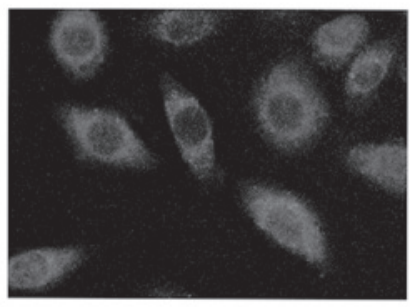

G

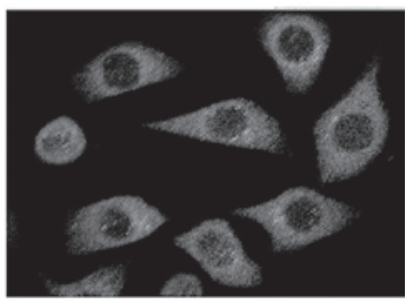

$\mathbf{H}$

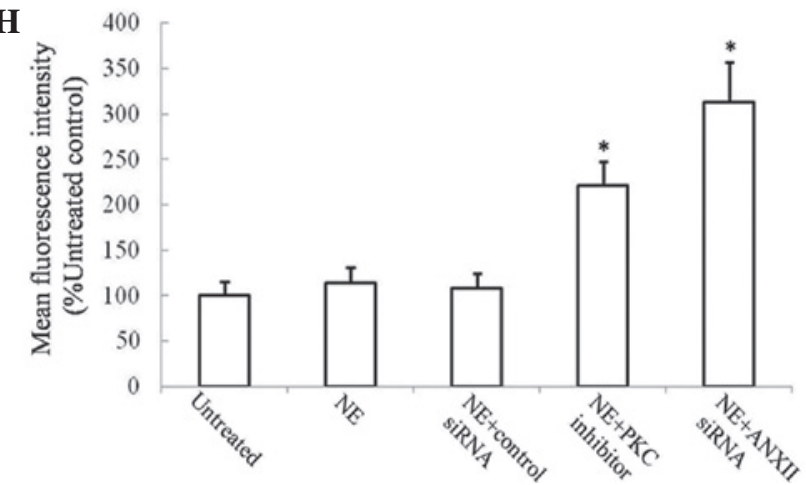

Figure 3. Annexin II (ANXII) is required for neutrophil elastase (NE)-stimulated mucin 5ac (MUC5AC) secretion. (A) Human bronchial epithelial (16HBE) cells were transfected with ANXII siRNA or the control vector. ANXII protein levels were detected by western blotting. (B) MUC5AC secretion into the cell supernatant was measured by enzyme-linked immunosorbent assay (ELISA). The concentration of MUC5AC in 16HBE cells incubated in serum-free Dulbecco's modified Eagle's medium for $12 \mathrm{~h}$ was set as the standard. The cell supernatant was determined and compared with the standard. * $<<0.05$ compared with the untreated group; ${ }^{\wedge} \mathrm{P}<0.05$ compared with the NE stimulating group; ${ }^{\sharp} \mathrm{P}>0.05$ between the two groups; $\mathrm{n}=6$. (C-G) $\mathrm{MUC} 5 \mathrm{AC}$ retained in the endochylema was visualised with cell immunochemistry (original magnification, x400). (C) Representative image of untreated 16HBE cells. (D) Representative image of NE-stimulated 16HBE cells. (E) Representative image of the control siRNA-transfected and NE-stimulated 16HBE cells. (F) Representative image of the protein kinase-C (PKC) inhibitor pretreated and NE-stimulated 16HBE cells. (G) Representative image of ANXII siRNA-transfected and NE-stimulated 16HBE cells. $(\mathrm{H})$ The concentration of intracytoplasmic-retained MUC5AC was quantitated by comparing the fluorescence intensity of the treated sample with that of the negative control. At least 20 cells were evaluated for each condition. ${ }^{*} \mathrm{P}<0.05$ compared with the other three groups mentioned in cartogram.

membrane formed by ANXII in stimulated neuroendocrine cells (19). Direct evidence has been obtained for the role of ANXII in exocytosis.

ANXII exists either as a monomer (p36) or as a section of a heterotetrameric complex (p90) with S100A10, a protein of $11 \mathrm{kDa}$, which is referred to as p11. In the heterotetrameric p90 complex, the central S100A10 dimer links two ANXII chains in a highly symmetrical manner, creating a scaffold that is capable of bridging the opposing membrane surfaces. Several observations have suggested that the ANXII-S100A10 heterotetrameric complex targets the cell surface and the cortical cytoskeleton (20).
In neuroendocrine cells, ANXII promotes monosialotetrahexosylganglioside-containing lipid microdomains that are required for calcium-related exocytosis (12). Soluble SNAREs present at the plasma membrane have been reported to be the membrane fusion sites for vesicle exocytosis $(21,22)$. ANXII has been revealed to colocalise with SNAP-23, which is abundant in non-neuronal cells and is responsible for the secretion of mucin granules (23). Therefore, it was investigated whether ANXII was responsible for MUC5AC secretion. There is evidence that reactive oxygen species, inflammation and hypoxia activate the expression of ANXII $(24,25)$. It was demonstrated that 
following stimulation with NE, ANXII mRNA transcription and protein levels increased by $\sim 2$-fold at their peak levels. Immunohistochemistry on the NE-stimulated 16HBE cells allowed the visualisation of the distribution of ANXII in stimulated hypersecretion cells. Similar to what has been reported in chromaffin cells (10), it was established that ANXII is recruited to the cell membrane in stimulated $16 \mathrm{HBE}$ cells. As demonstrated in mesangial cells in vitro, ANXII is phosphorylated by PKC (14) and a synthetic peptide corresponding to the $\mathrm{NH}_{2}$-terminus of ANXII, which contains the PKC phosphorylation site and inhibits catecholamine secretion in chromaffin cells (26). Similarly, bisindolylmaleimide I was used to inhibit the phosphorylation of ANXII and revealed an attenuation in the peripheral recruitment of ANXII in NE-stimulated 16HBE cells. These data suggest that the induction of ANXII expression and its recruitment to the cell membrane in $16 \mathrm{HBE}$ cells upon NE stimulation is dependent on the PKC pathway.

Despite 20 years of extensive study, the precise function of ANXII remains unknown. In particular, the role of ANXII in non-neuroendocrine cell secretion has yet to be clarified. According to a previous study, NE increases the novel synthesis of MUC5AC following treatments that last $>4 \mathrm{~h}$, primarily by enhancing MUC5AC mRNA stability (27). It was established that $4 \mathrm{~h}$ was the adequate stimulation time to investigate secretion of MUC5AC granules induced by NE (28). A specific siRNA targeting ANXII was synthesised to inhibit the endogenous production of ANXII in 16HBE cells. Using these methods, it was determined that ANXII is essential for MUC5AC secretion.

The present study provides evidence of ANXII involvement in the mechanisms of MUC5AC secretion in airway epithelial cells. It may aid in the understanding of the specific mechanism of MUC5AC secretion and provide a novel therapy for the management of local and systemic diseases in mucus hypersecretion.

\section{Acknowledgements}

This study was supported by grant from the National Nature Science Foundation of China (grant no. 81370111) and the China-Russia Cooperation Research Foundation (grant no. 31211120168).

\section{References}

1. Ordonez CL, Khashayar R, Wong HH, et al: Mild and moderate asthma is associated with airway goblet cell hyperplasia and abnormalities in mucin gene expression. Am J Respir Crit Care Med 163: 517-523, 2001.

2. Turner $\mathrm{J}$ and Jones CE: Regulation of mucin expression in respiratory diseases. Biochem Soc Trans 37: 877-881, 2009.

3. Voynow JA, Fischer BM, Malarkey DE, et al: Neutrophil elastase induces mucus cell metaplasia in mouse lung. Am J Physiol Lung Cell Mol Physiol 287: L1293-1302, 2004.

4. Kohri K, Ueki IF and Nadel JA: Neutrophil elastase induces mucin production by ligand-dependent epidermal growth factor receptor activation. Am J Physiol Lung Cell Mol Physiol 283: L531-L540, 2002.

5. Jiang DP, Li Q, Yang J, Perelman JM, Kolosov VP and Zhou XD: Scutellarin attenuates human-neutrophil-elastaseinduced mucus production by inhibiting the PKC-ERK signaling pathway in vitro and in vivo. Am J Chin Med 39: 1193-1206, 2011.
6. Roghanian A, Drost EM, MacNee W, Howie SE and Sallenave JM: Inflammatory lung secretions inhibit dendritic cell maturation and function via neutrophil elastase. Am J Respir Crit Care Med 174: 1189-1198, 2006.

7. Benz J and Hofmann A: Annexins: from structure to function. Biol Chem 378: 177-183, 1997.

8. Paumet F, Rahimian V and Rothman JE: The specificity of SNARE-dependent fusion is encoded in the SNARE motif. Proc Natl Acad Sci USA 101: 3376-3380, 2004

9. Chattopadhyay S, Sun P, Wang P, Abonyo B, Cross NL and Liu L: Fusion of lamellar body with plasma membrane is driven by the dual action of annexin II tetramer and arachidonic acid. J Biol Chem 278: 39675-39683, 2003.

10. Umbrecht-Jenck E, Demais V, Calco V, Bailly Y, Bader MF and Chasserot-Golaz S: S100A10-mediated translocation of annexin-A2 to SNARE proteins in adrenergic chromaffin cells undergoing exocytosis. Traffic 11: 958-971, 2010.

11. Chasserot-Golaz S, Vitale N, Sagot I, Delouche B, Dirrig S, Pradel LA, Henry JP, Aunis D and Bader MF: Annexin II in exocytosis: catecholamine secretion requires the translocation of p36 to the subplasmalemmal region in chromaffin cells. J Cell Biol 133: 1217-1236, 1996.

12. Chasserot-Golaz S, Vitale N, Umbrecht-Jenck E, Knight D, Gerke V and Bader MF: Annexin 2 promotes the formation of lipid microdomains required for calcium-regulated exocytosis of dense-core vesicles. Mol Biol Cell 16: 1108-1119, 2005.

13. Sarkar P and Hayes BE: Proteomic profiling of rat lung epithelial cells induced by acrolein. Life Sci 85: 188-195, 2009.

14. Oudinet JP, Russo-Marie F, Cavadore JC and Rothhut B: Protein kinase C-dependent phosphorylation of annexins I and II in mesangial cells. Biochem J 292: 63-68, 1993.

15. Vestbo J: Epidemiological studies in mucus hypersecretion. Novartis Found Symp 248: 3-19, 277-282, 2002.

16. Rogers DF: Physiology of airway mucus secretion and pathophysiology of hypersecretion. Respir Care 52: 1134-1149, 2007.

17. Foster WM, Adler KB, Crews AL, Potts EN, Fischer BM and Voynow JA: MARCKS-related peptide modulates in vivo the secretion of airway Muc5ac. Am J Physiol Lung Cell Mol Physiol 299: L345-352, 2010

18. Park JA, Crews AL, Lampe WR, Fang S, Park J and Adler KB: Protein kinase $\mathrm{C}$ delta regulates airway mucin secretion via phosphorylation of MARCKS protein. Am J Pathol 171: 1822-1830, 2007.

19. Senda T, Okabe T, Matsuda M and Fujita H: Quick-freeze, deep-etch visualization of exocytosis in anterior pituitary secretory cells: localization and possible roles of actin and annexin II. Cell Tissue Res 277: 51-60, 1994.

20. Deora AB, Kreitzer G, Jacovina AT and Hajjar KA: An annexin 2 phosphorylation switch mediates p11-dependent translocation of annexin 2 to the cell surface. J Biol Chem 279: 43411-43418, 2004.

21. Behrendorff N, Dolai S, Hong W, Gaisano HY and Thorn P: Vesicle-associated membrane protein 8 (VAMP8) is a SNARE (soluble N-ethylmaleimide-sensitive factor attachment protein receptor) selectively required for sequential granule-to-granule fusion. J Biol Chem 286: 29627-29634, 2011.

22. Jones LC, Moussa L, Fulcher ML, et al: VAMP8 is a vesicle SNARE that regulates mucin secretion in airway goblet cells. J Physiol 590: 545-562, 2012

23. Wang P, Chintagari NR, Gou D, Su L and Liu L: Physical and functional interactions of SNAP-23 with annexin A2. Am J Respir Cell Mol Biol 37: 467-476, 2007.

24. Madureira PA, Hill R, Miller VA, Giacomantonio C, Lee PW and Waisman DM: Annexin A2 is a novel cellular redox regulatory protein involved in tumorigenesis. Oncotarget 2: 1075-1093, 2011.

25. Genetos DC, Wong A, Watari S and Yellowley CE: Hypoxia increases Annexin A2 expression in osteoblastic cells via VEGF and ERK. Bone 47: 1013-1019, 2010.

26. Chasserot-Golaz S, Vitale N, Sagot I, et al: Annexin II in exocytosis: catecholamine secretion requires the translocation of p36 to the subplasmalemmal region in chromaffin cells. J Cell Biol 133: 1217-1236, 1996.

27. Voynow JA, Young LR, Wang Y, Horger T, Rose MC and Fischer BM: Neutrophil elastase increases MUC5AC mRNA and protein expression in respiratory epithelial cells. Am J Physiol 276: L835-843, 1999.

28. Zhou J, Perelman JM, Kolosov VP and Zhou X: Neutrophil elastase induces MUC5AC secretion via protease-activated receptor 2. Mol Cell Biochem 377: 75-85, 2013. 